\title{
Effect of Life Skills Training Based on Effective Communication and Emotion Management on Marital Satisfaction, Hopefulness and Self Confidence in Spouses of Spinal Cord Injurred Veterans
}

\section{ART I C L E INF O}

\section{Article Type}

Original Research

\section{Authors}

Namavar S. ${ }^{1} M A$

Ghodrati S. ${ }^{* 1} P h D$,

Gholami Heydarabadi Z. ${ }^{1} \mathrm{PhD}$

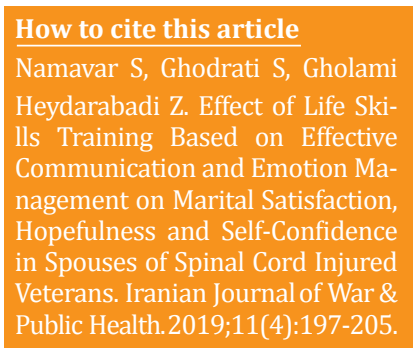

${ }^{1}$ Psychology Department, Humanities Faculty, West Tehran Branch, Islamic Azad University, Tehran, Iran

\section{*Correspondence \\ Address: Humanities Faculty, West Tehran Branch, Islamic Azad Uni- versity, Simaye Iran Street, Sanat Square, Tehran, Iran Postal Code: 8683114676 \\ Phone: +98 (21) 88074907 \\ Fax: +98 (21) 22880216 \\ sima.ghodrati17@yahoo.com}

\section{Article History}

Received: March 20, 2019

Accepted: July 29, 2019

ePublished: December 21, 2019

\section{A B S T R A C T}

Aims War causes physical and psychological problems for people who are directly and indirectly involved in the war, including spouses of veterans. The aim of this study was to investigate the effectiveness of life skills training, including emotion management and effective communication skills on marital satisfaction, hopefulness, and self-confidence in spouses of spinal cord injured veterans of Tehran.

Materials \& Methods This semi-experimental research with pre-test and post-test design and control group was carried out on 30 spouses of spinal cord injured veterans who were residents of Tehran in 2018 by convenience sampling. The subjects were classified into control and experimental groups $(\mathrm{N}=15)$. Data were collected through standard enrich marital satisfaction, Schneider's hopefulness, and Bernreuter personality questionnaires. The pre-test was implemented for each of the 30 subjects. Then, the experimental group received 12 sessions of intervention including 7 sessions of emotion management skills training and 5 sessions of effective communication training and the post-test was performed again. Data were analyzed by SPSS 22 software using the paired t-test.

Findings There was no significant difference between mean scores of hopefulness, selfconfidence and marital satisfaction in control group in the pre-test and post-test step ( $p>0.05)$, however, the mean scores of these variables in the experimental group showed a significant increase in the post-test compared to the pre-test $(p<0.05)$.

Conclusion Skill training of emotion management and effective communication are effective in enhancing marital satisfaction, hopefulness, and self-confidence of spouses of spinal cord injured veterans.

Keywords Emotion; Communication; Marriage; Satisfaction; Hopefulness; Self-Confidence

\section{I T A T I O N L I N KS}

[1] Power technologies in the soft ... [2] The effect of life skills training ... [3] The effectiveness of life skills training ... [4] Effectiveness of emotional schema ... [5] The effects of life skills training on ... [6] The relationship between self-confidence ... [7] The effect of acceptance and ... [8] The effect of life skills education ... [9] The effect of life skills training ... [10] Practical stress management ... [11] Plutchik's wheel of ... [12] Emotion regulation in adolescents ... [13] The effectiveness of life skills training ... [14] The efficacy of life skills training on ... [15] Exploring the effect of life skills ... [16] The effectiveness of life skills training ... [17] Effective interactions: communication ... [18] Communication skills training in the ... [19] The effect of life skills training on ... [20] Effect of life skills counseling on marital ... [21] Effectiveness of Life Skills Training ... [22] Effectiveness of life skills training in ... [23] The impact of life skills training on ... [24] Examining the effect of life skills training ... [25] Aspects of marital satisfaction ... [26] The impact of life skills training on ... [27] Effectiveness of life skills training on ... [28] Effectiveness of acceptance and ... [29] Family and marriage assessment ... [30] Reliability and validity of the Persian versions ... [31] The will and the ways ... [32] Effectiveness of group ... [33] Psychometric characteristics of ... [34] Comparison of selfconfidence and ... [35] An evaluation of the reliability and validity and ... [36] A history of the early days of personality ... [37] Effects of social learning model training on ... [38] Emotion regulation: affective, cognitive ... [39] Talking and listening together: couple ... [40] The effectiveness of communication skills ... [41] The effect of life skills training on marital ... [42] The effect of life skills training on ... [43] Efficacy of training life skills on ... [44] Does couples' communication predict ... [45] Immediate effect of couple relationship ... [46] Hospital employees improve basiclife... [47] Studying the relationship between the trust in ... [48] The role of communication skills training and ... 
غيرهستقيم در جنگ دركير بودهاند. از جمله اين افراد همسران

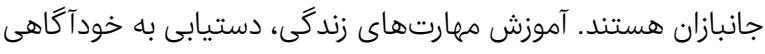
و شيوه درست كنترل احساسات و مقابله با استرس رانيان را ممكن

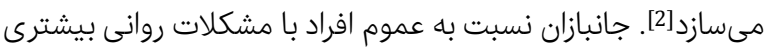

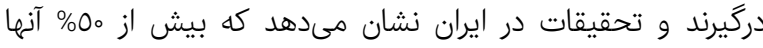

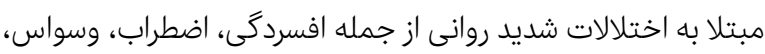

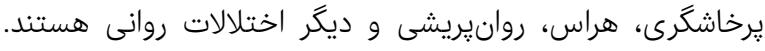

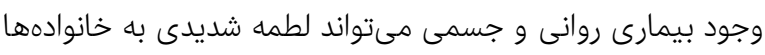

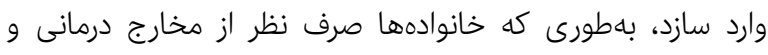

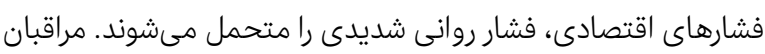

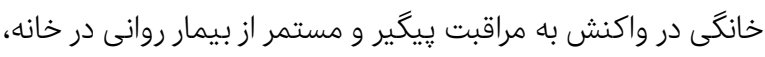

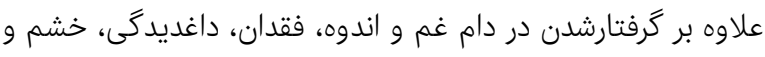

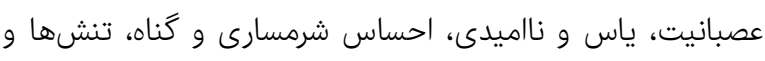

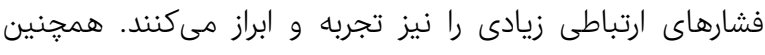

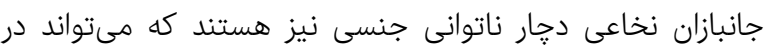

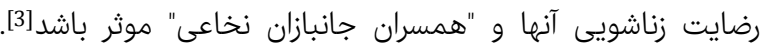

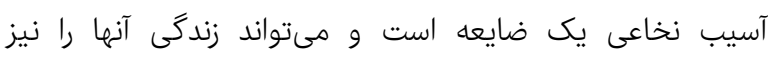

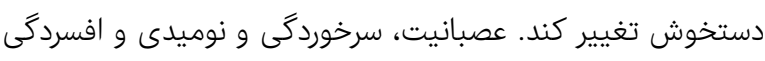

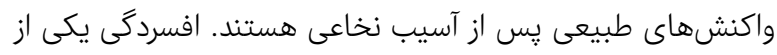

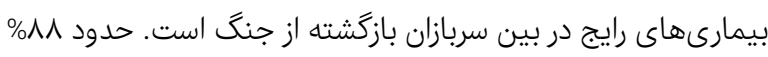

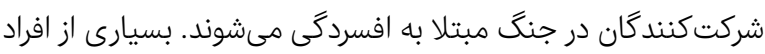

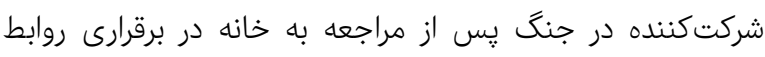
اجتماعى و رابطه صميمانه با خانواده و اطرافيان با مشكلاتى مواجه

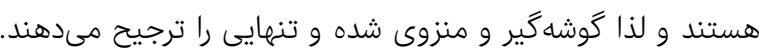

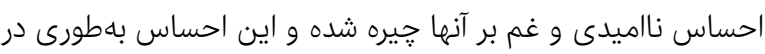

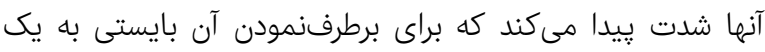

روانشناس يا روانيزشك مراجعه نمايند [4]. رضايت زناشويى را احساس عينى خشنودى، رضايت، انطباق برانين

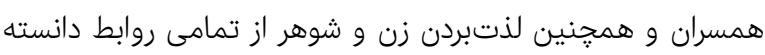

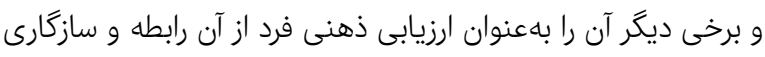

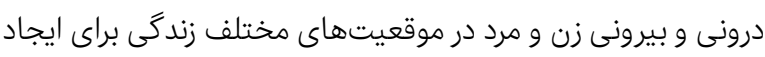

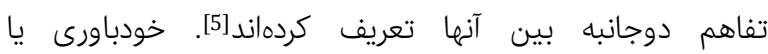

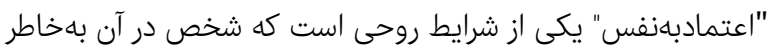

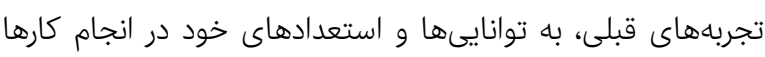
بهطور موفقيتآميز اعتماد و باور دارد. خصوصيت دارئ دارابودن اعتماد الجياد

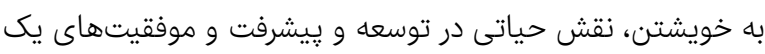

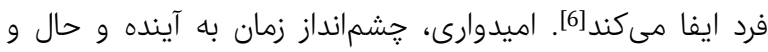

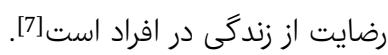

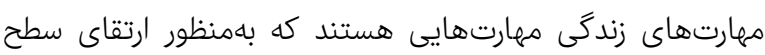

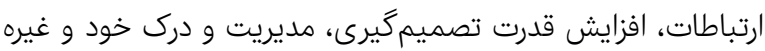

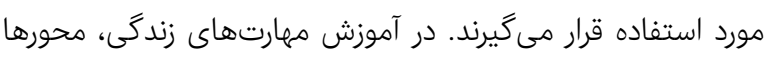

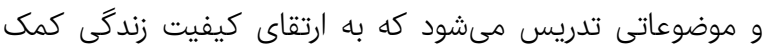

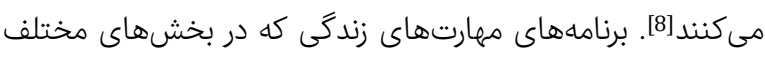
جهان استفاده مىشود و توسط سازمان بهداشت جهانى ارايه شده،
تاثير آموزش مهارتهاى زندگى مبكى مبتنى بر ارتباط

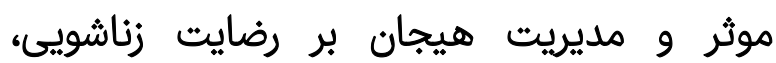
اميدوارى و اعتمادبهنفس در همسران جانبازان نخاعى

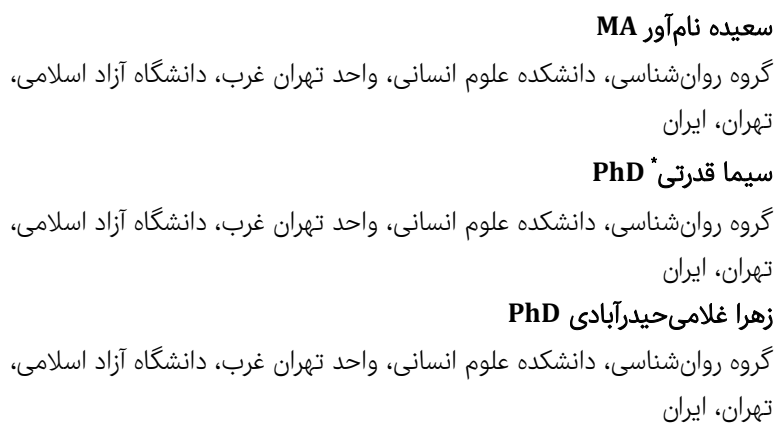

جكيده اهداف: جنگ موجب بروز مشكلات جسمى و روانى براى افرادى مى اشود كه بهطور

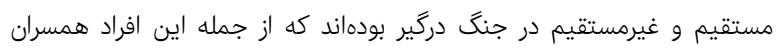

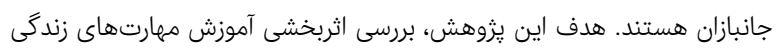

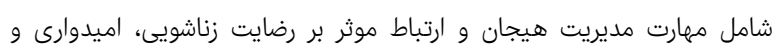

اعتمادبهنفس در همسران جانبازان نخاعى بود مدرد

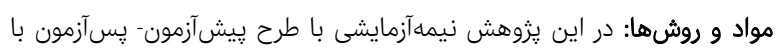

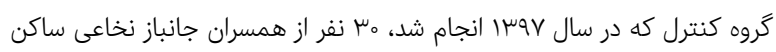

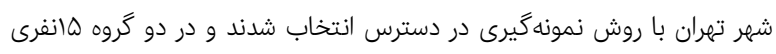

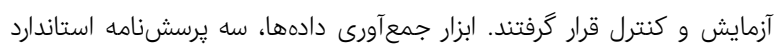

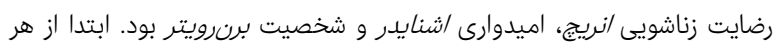

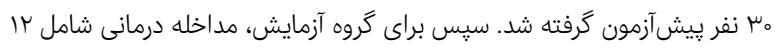

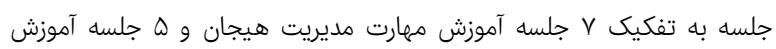

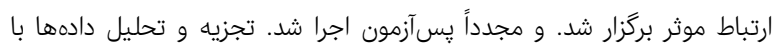

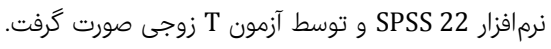

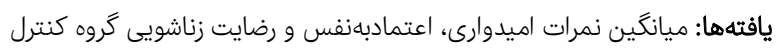

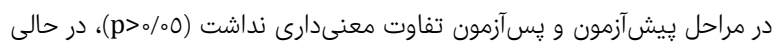

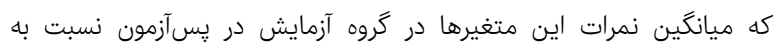

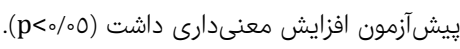

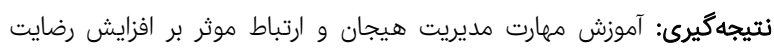

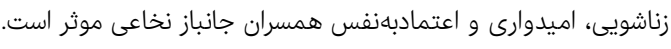

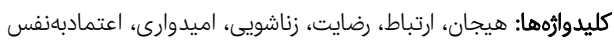

تاريخ دريافت: توبر

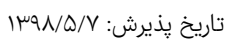
نويسنده مسئول: sima.ghodrati17@yahoo.com

\section{مقدمه}

جنگ نوعى منازعه خشونتآميز سياسى است كه بين كروههاى انسانى رخ مىدهد. اين منازعه سياسى اجتماعى با توجه به به ماهيت،

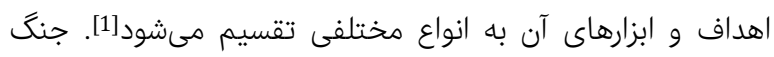

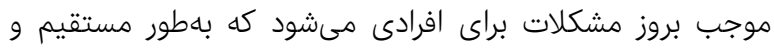


تاثير آموزش مهارتهاى زندگى مبتنى بر ارتباط موثر و مديريت هيجان بر رضايت زناشويى... 199

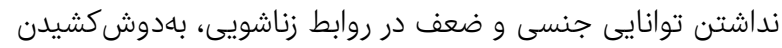

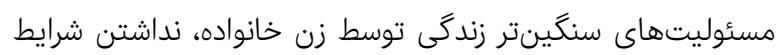

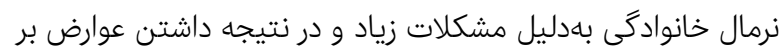

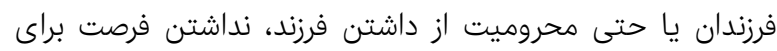

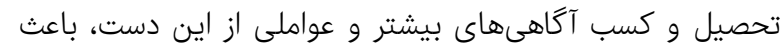
شد كه همسران جانبازان نخاعى بيش از شايد آهاي بسيارى از از زنان

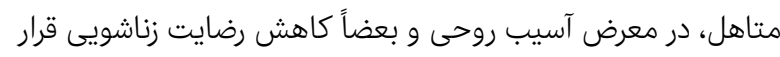

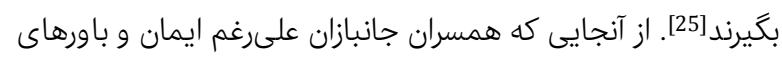

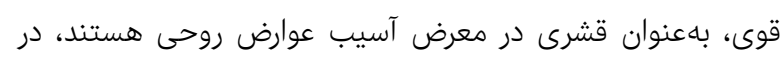

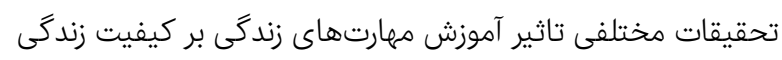

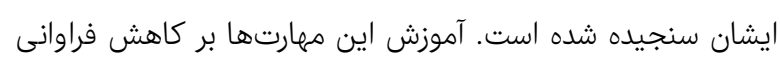
نشخوارهاى فكرى افسردهاز در همسران جانبازان تاثيرگذار بود [2].

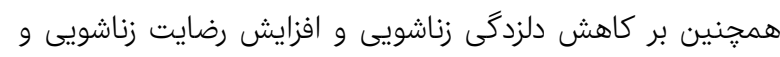

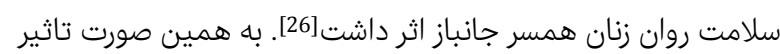

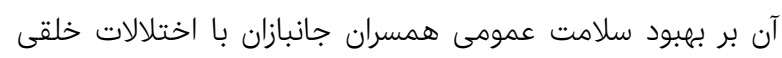
تاييد شد[ن]

هر : جند همسران جانبازان نخاعى سالهاست كه با مشكلات آنها

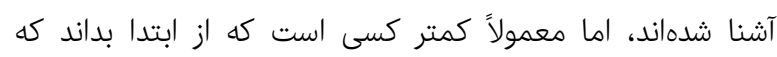

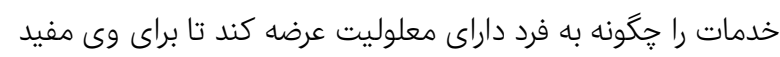

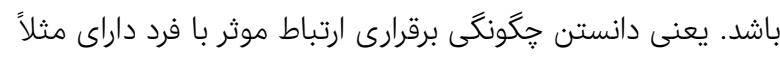

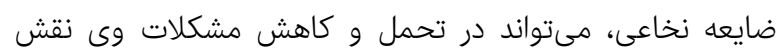

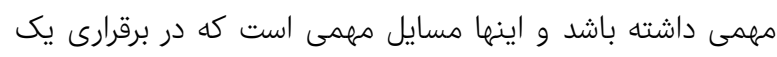

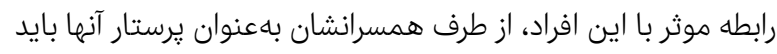

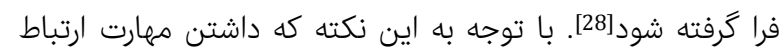

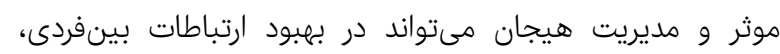

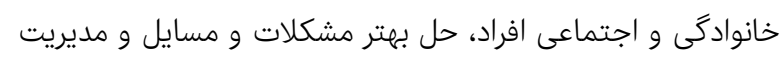

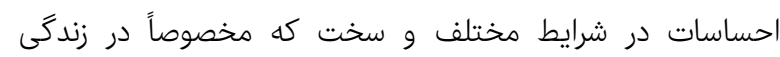

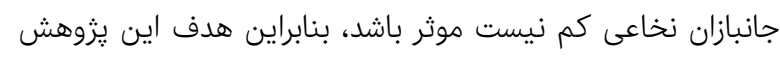

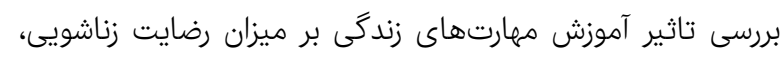
اميدوارى و اعتمادبهنفس همسران جانباز نخاعى بود.

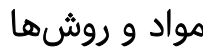

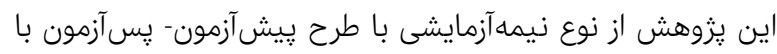

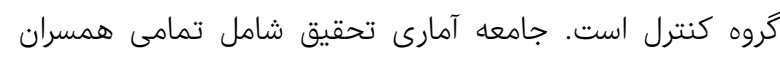

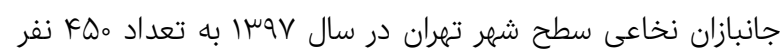

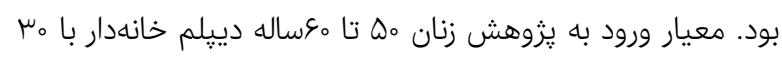

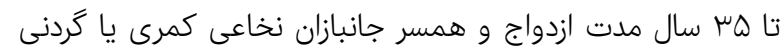

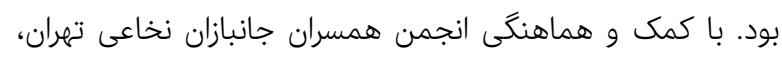

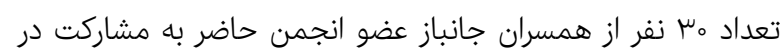

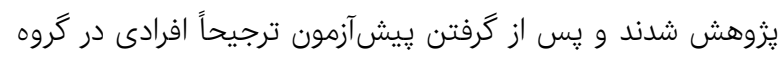

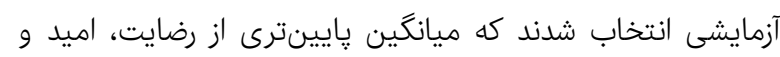

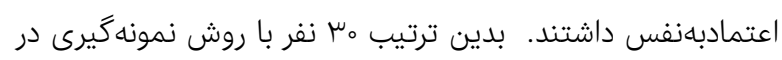

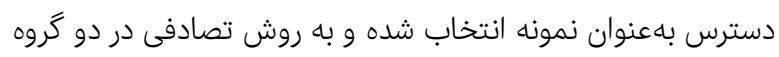
هانفره آزمايش و كنترل قرار كرفتند.

به برنامهاى عمل زرايانه و كارآمد تبديل شده است. مهارتهاى

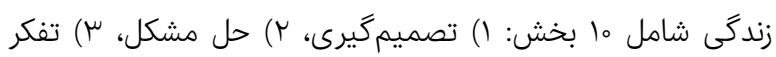

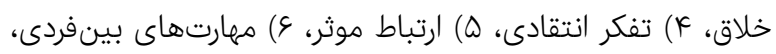

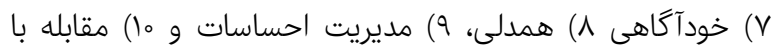

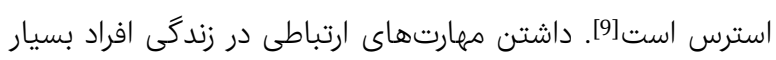

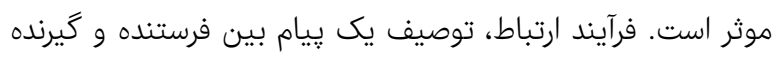

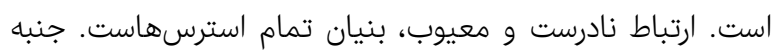

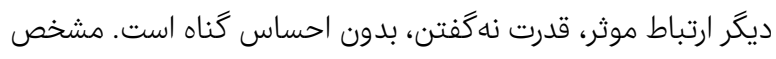
شده كه در ابراز عقيده (جراتمندى)، كمترين ميزان استرس ايجاد

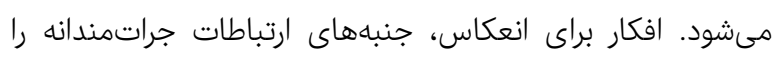

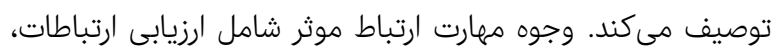

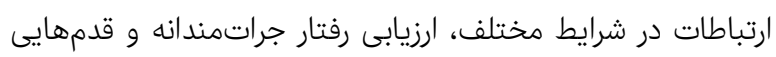

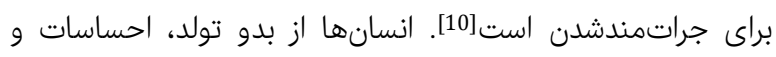

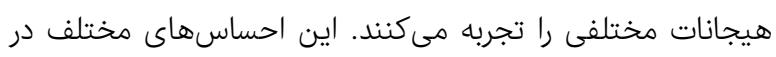

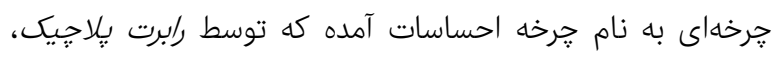
دانشمند آمريكايى طراحى شده است. احساسات شامل احساسات

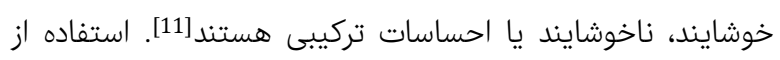

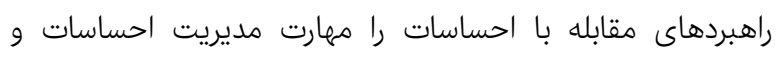

$$
\text { هيجان مىنامند [12]. }
$$

يزوهشها نشان دادهاند كه ارتقاى رضايت زناشويى با آموزش

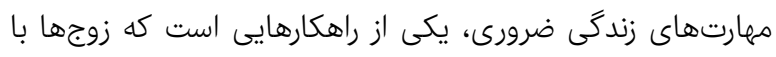

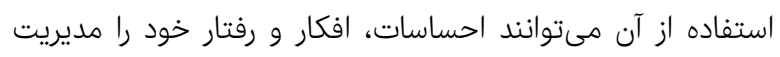

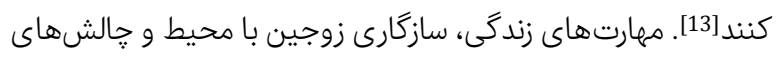

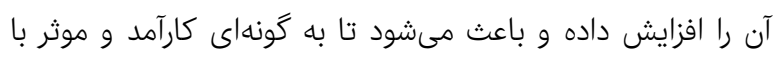
مسايل محيط خانوادگى، شغلى و اجتماعى روباهرو شوند و رضايت

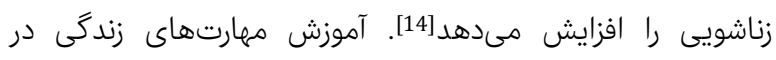
افزايش شاخص مثبت سازگارى روانى (ابراز وجود و اعتمادبهنفس) آنسي)

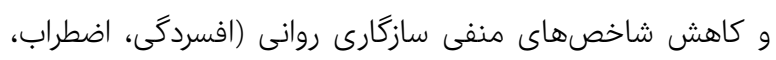

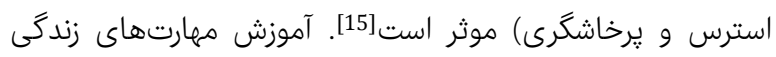

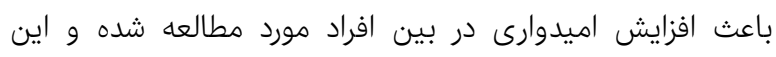

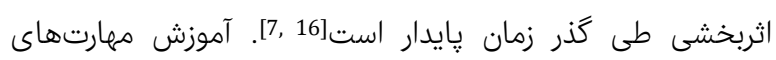

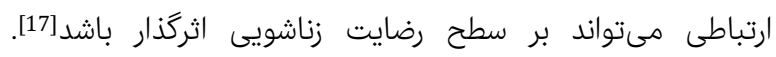

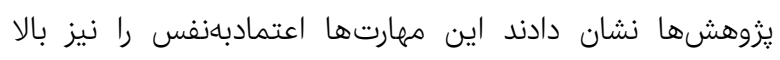

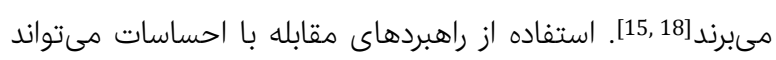
شدت تجربيات عاطفى منفى را كاهش و توانايى اعضاى خانواده

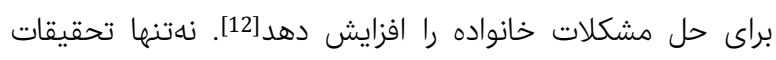

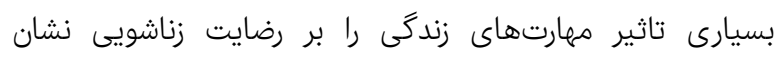

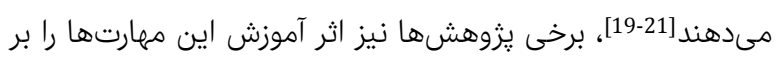

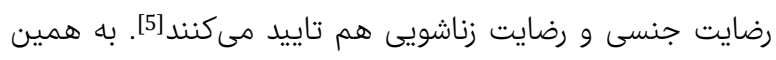
صورت يزوهشهايى نشان دادند كه آموزش اين مهارتهات نها بر بر افزايش

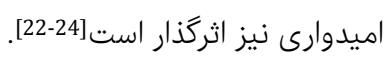

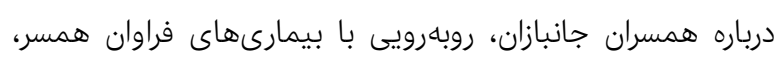

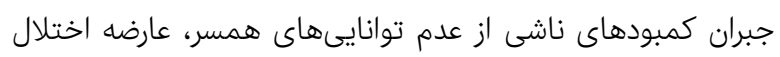
سندروم يس از سانحه كه دامنكير اغلب قربانيان جنگ استى است، 
همسانى درونى آزمون معادل M9/ بود.

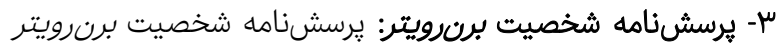
يك آزمون شخصيت است كه توسط رابرت جى برنرويتر در سال

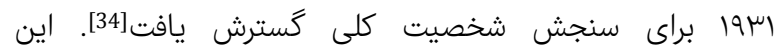

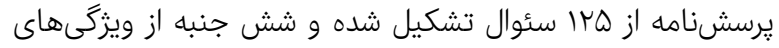

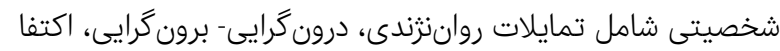

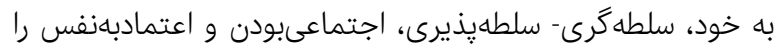

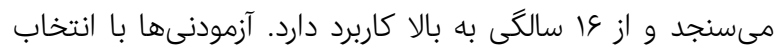

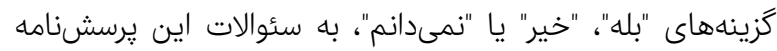

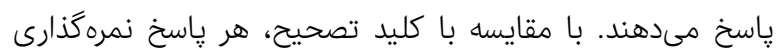

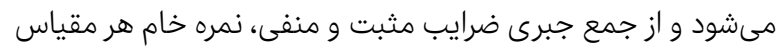

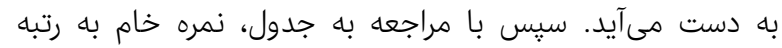

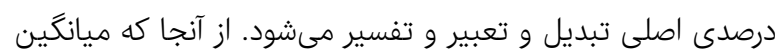

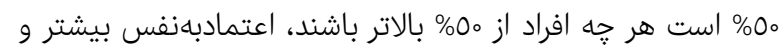

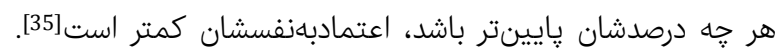

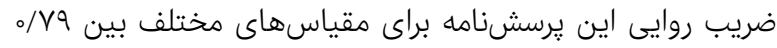

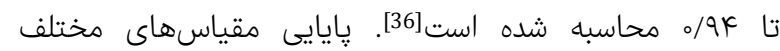

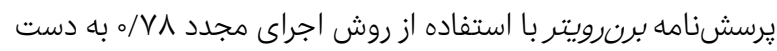

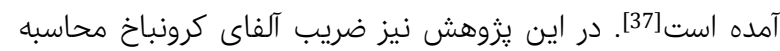

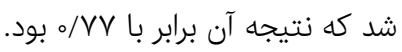

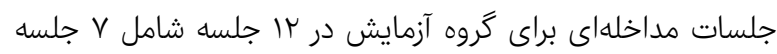
آموزش مديريت هيجان براساس بسته آموزشى اصلاح راهبردهاى

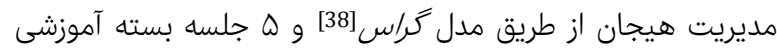

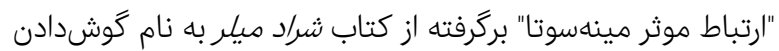

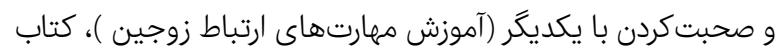

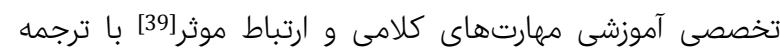

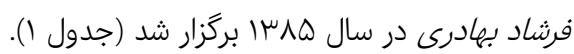

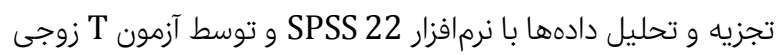

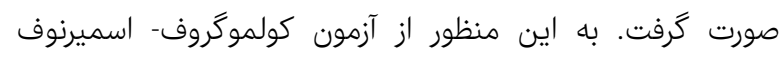
بهنوان آزمون يِيشفرض براى بررسى نرمالبودن توزيع دادهها

استفاده شد.

\section{يافتهها}

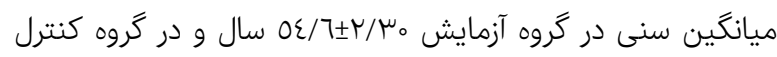
س// مي

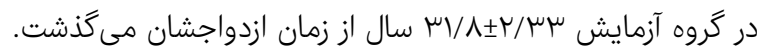

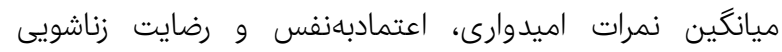

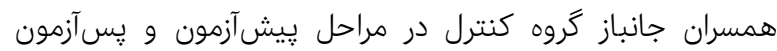

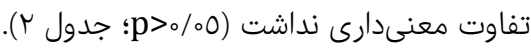

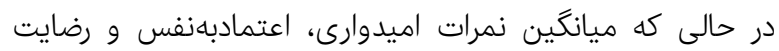

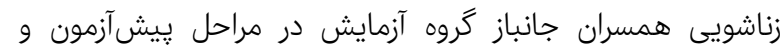

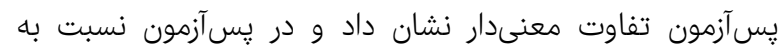

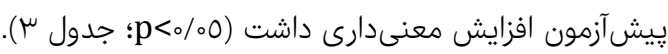

با معرفى توسط انجمن جانبازان نخاعى، همسران جانبازان نان نخاعى

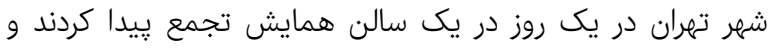
فرآيند و هدف يزوهش براى همه توضيح داده شد. با شروع دوره و

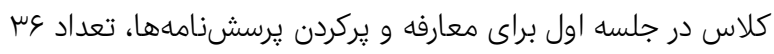
نفر فقط در جلسه حاضر شدند. يِيشآزمون از همه اين افراد گرفته

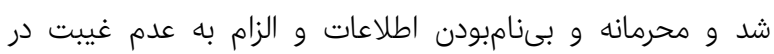
جلسات و حضور در تمامى rا جلسه و حداكثر اجازه يك جلسه

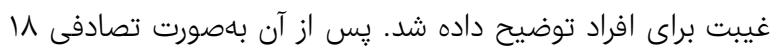

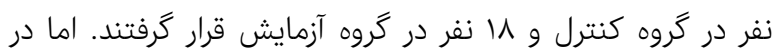

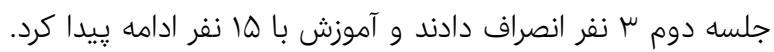

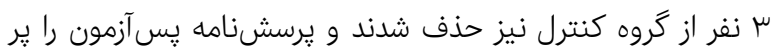

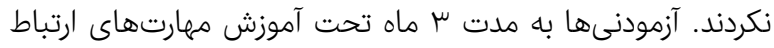

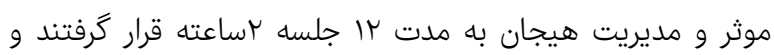

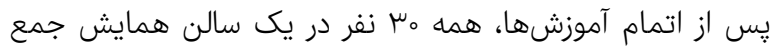
شده و يرسشنامهها را دوباره تكميل نمودند.

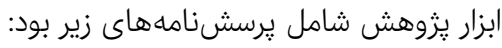

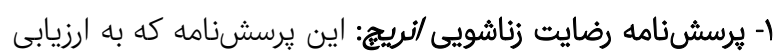

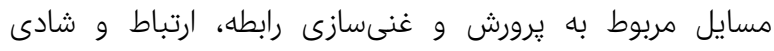

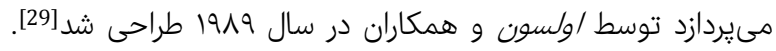

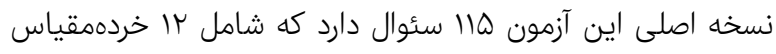

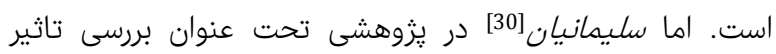
تفكرات غيرمنطقى براساس رويكرد شناختى بر نارضايتى زناشويى،

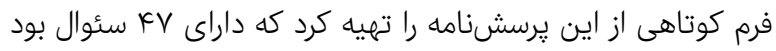

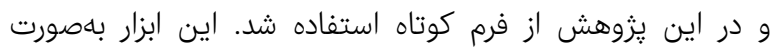

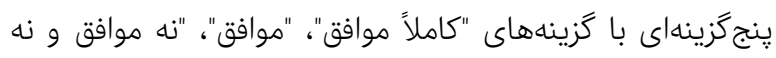

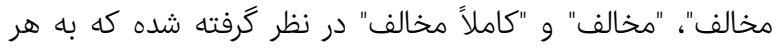

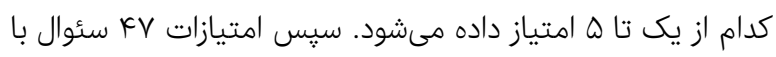

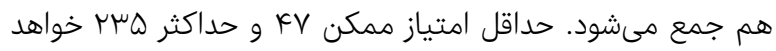

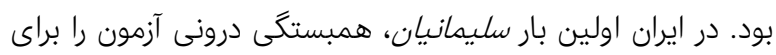

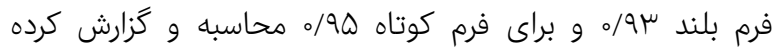

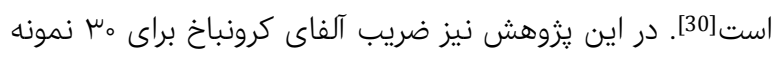

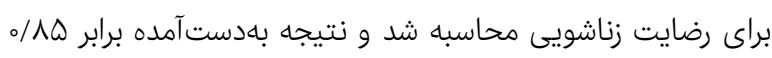

r- يرسشنامه اميدوارى/شنايدر: اين يرسشنامه كه توسط /شنايدر

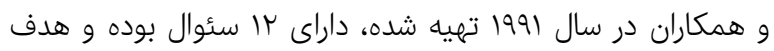

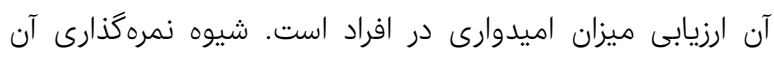

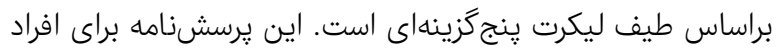

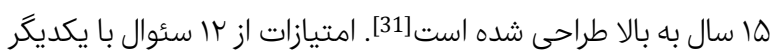

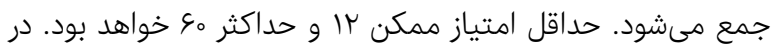

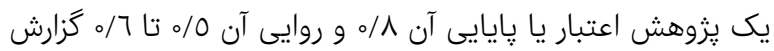

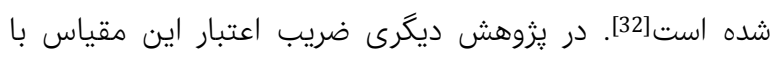

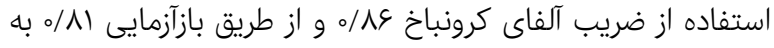

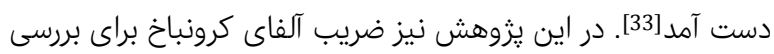




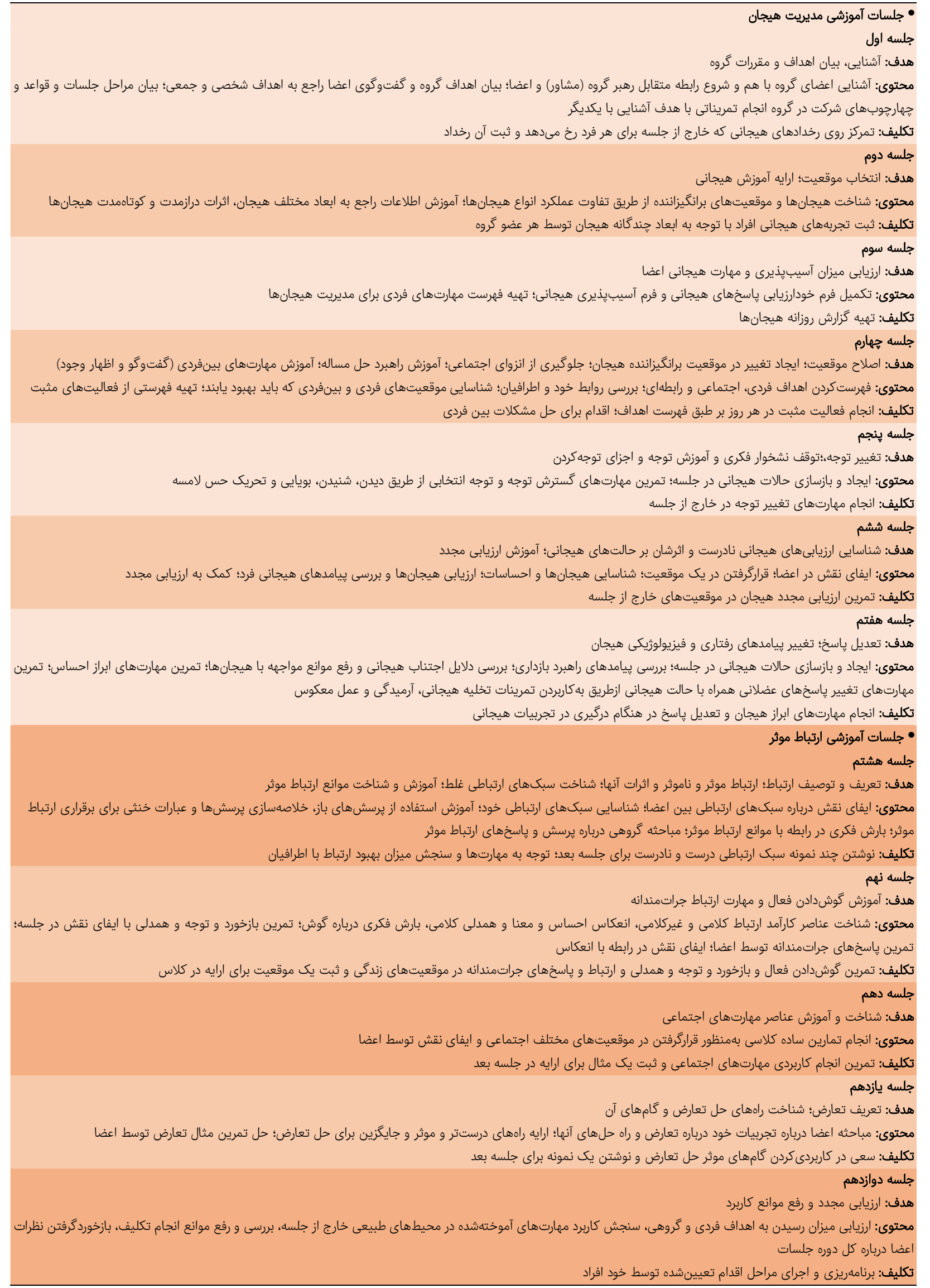




\begin{tabular}{|c|c|c|c|c|c|}
\hline \multicolumn{6}{|c|}{ جدول r) مقايسه ميانكين آمارى نمرات يِيشآزمون و يسآزمون اميدوارى، اعتمادبهنفس و رضايت زناشويى در گروه كنترل } \\
\hline حد پايين & حد بالا & سطح معنىدارى & مقدار t & نمرات & متغيرها \\
\hline$-r / V_{00}$ & $1 / 4 Y \varepsilon$ & -/VQV & 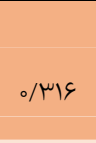 & 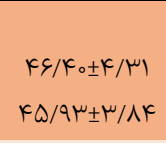 & |مِيش \\
\hline$-1 K / F k G$ & $\Delta / \wedge ९ \Delta$ & - /9人r & \% \% & $\begin{array}{l}r y / r V \pm 1 Q / \circ q \\
r y /|r \pm| K / q 1\end{array}$ & 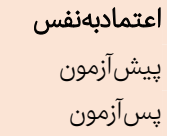 \\
\hline - & $8 / 9 \vee \wedge$ & ०/Q६ & $\%$ \%A & 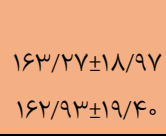 & رِيشآيت زناشون \\
\hline
\end{tabular}

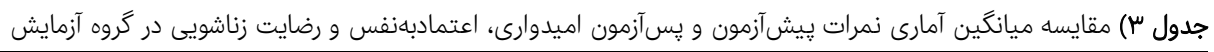

\begin{tabular}{|c|c|c|c|c|c|}
\hline حد پايين & حد بالا & سطح معنىدارى & مقدار t & نمرات & متغيرها \\
\hline$-11 / \Delta \wedge \mu$ & $-r / \& \wedge K$ & $\% \%$ K & $-\mu / k \mu q$ & $\begin{array}{l}\kappa Y / \& Y \pm \Delta / ৭ \Delta \\
\kappa \wedge / \Lambda \circ \pm \Delta / \vee \Lambda\end{array}$ & يِيش \\
\hline$-r I / F \wedge I$ & $-\circ / 9 \Delta \mu$ & $\% \mu q$ & $-r / r V q$ & 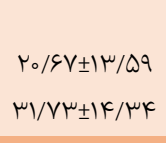 & 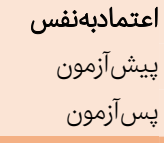 \\
\hline KF/KG & $-r / I \mu \Lambda$ & $\% \mu \mu$ & $-r / \mu G V$ & $\begin{array}{l}10 \circ / \circ \circ \pm \mu_{0} / \Delta K \\
\mid V Y / \Lambda_{\circ} \pm 1 Q / Q V\end{array}$ & يِيش آزآزمون زناشويى \\
\hline
\end{tabular}

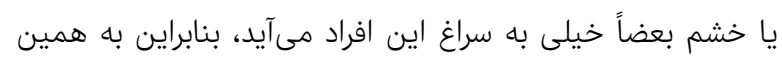

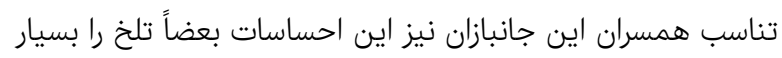

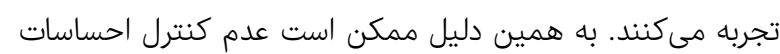

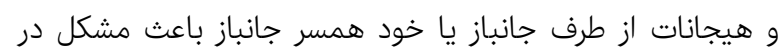

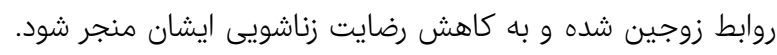

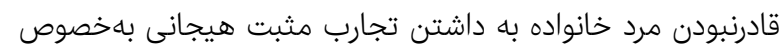

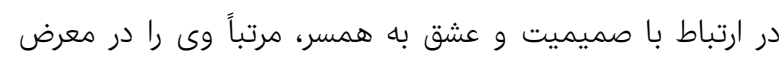

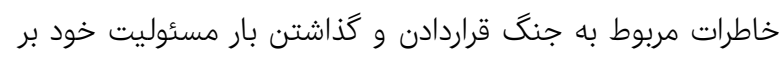

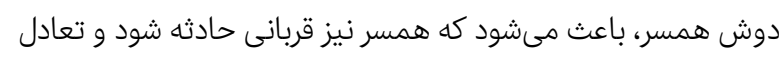

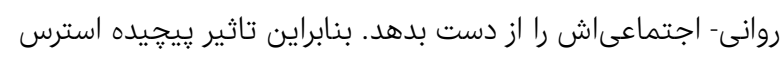

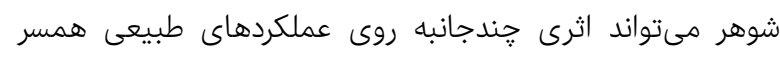

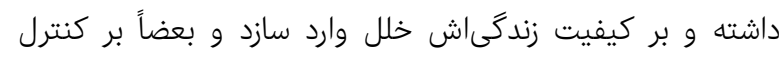

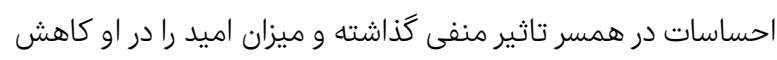

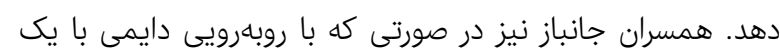

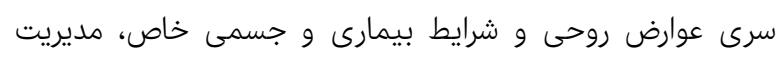

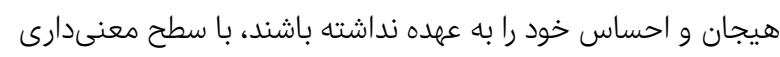

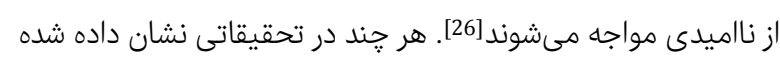

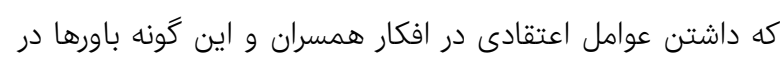

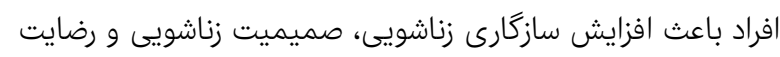

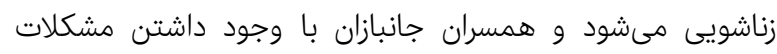

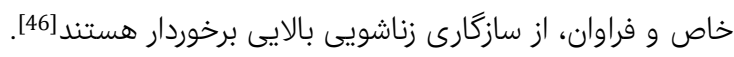

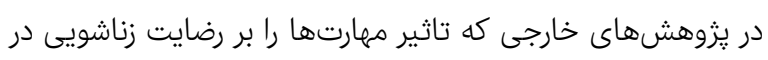

بحث

يزوهش حاضر با هدف بررسى اثربخشى آموزش مهارتهاى مديريت

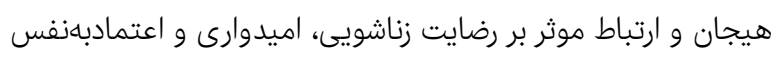

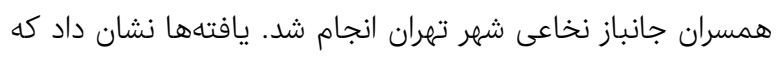

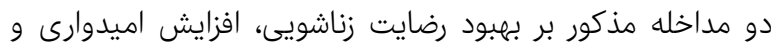

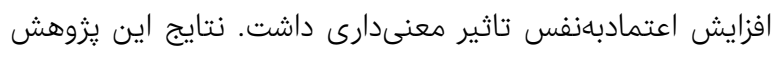

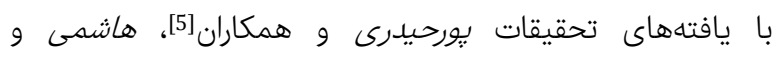

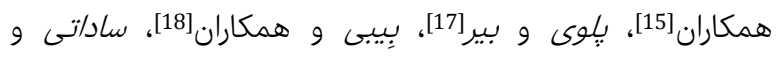

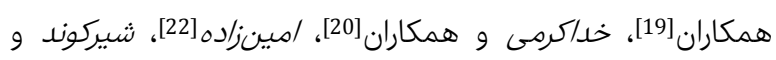

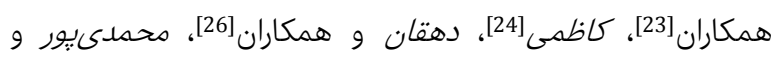

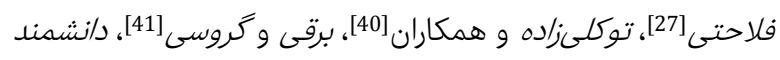

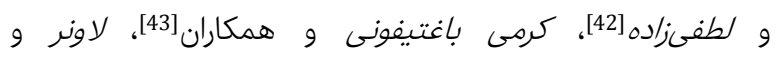

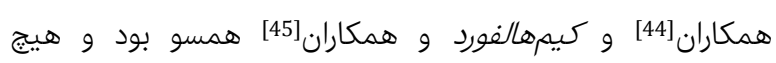

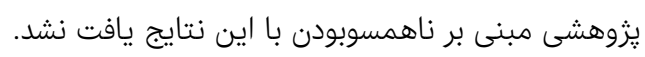

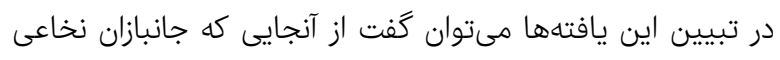

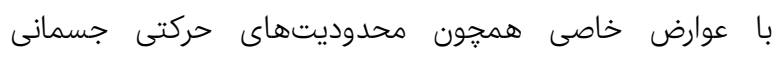

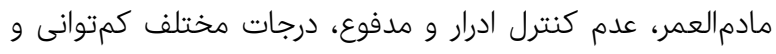

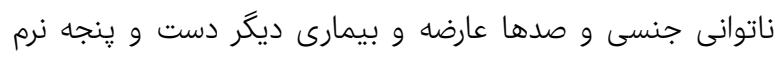

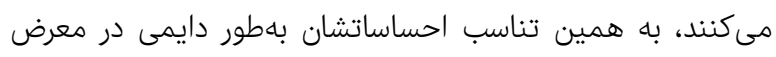

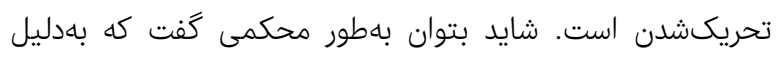

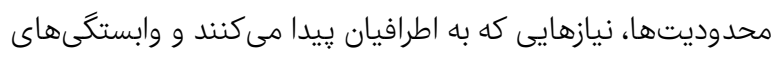

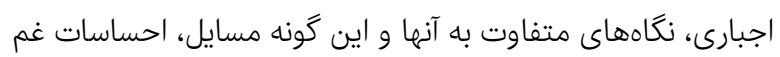




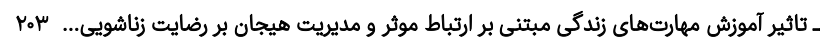

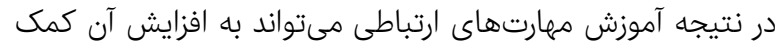

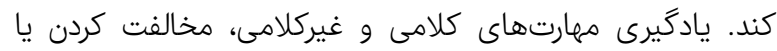

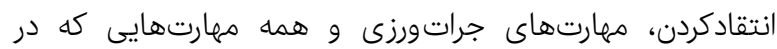

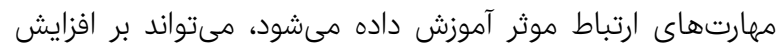

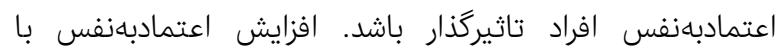

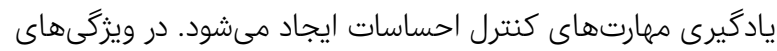

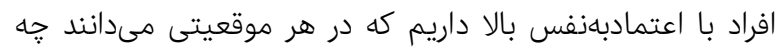

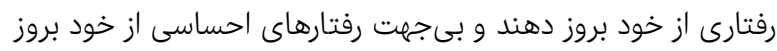

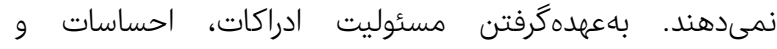
واكنشهاى خود و عدم فرافكنى نيز از جمله خصوصيات اين افراد است. بنابراين احساسات و اعتمادبهنفس به خودى خود به هيه هم وابسته هستند و تاثير مستقيم بر هم دارند [48].

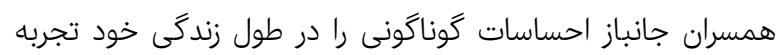

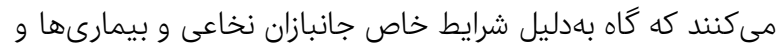

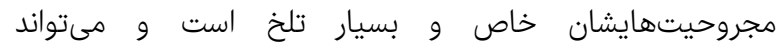
اعتمادبهنفس را كاهش دهد. در حالتى كه تجربيات كَاه تلخ،

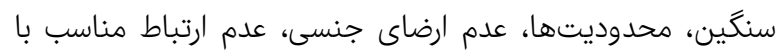

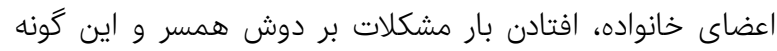

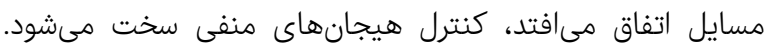

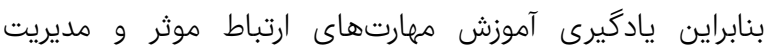

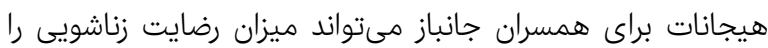

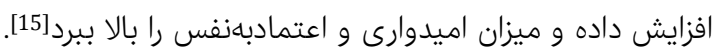

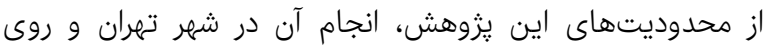

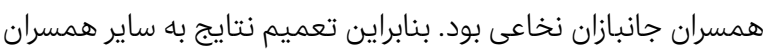

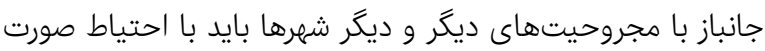

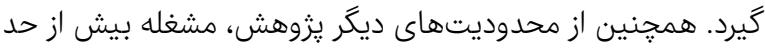

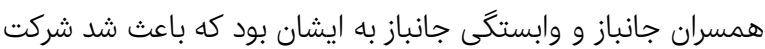

در كلاس و مشاركت در طرح بسيار با سختى صورت بكيرد.

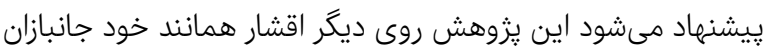

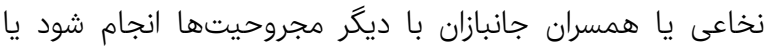

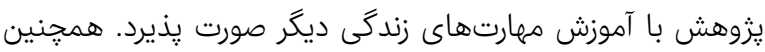

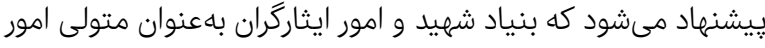

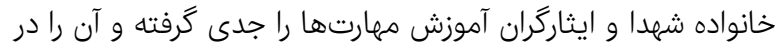
برنامه بخش و واحد روانشناسى بنياد بخنجاند.

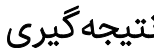

آموزش مهارت مديريت هيجان و ارتباط موثر بر رضايت زناشويى،

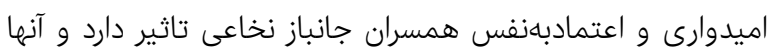

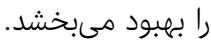

تشكر و قدردانى: از انجمن جانبازان نخاعى تهران و همسران

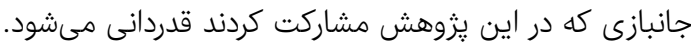

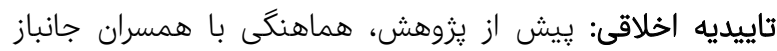

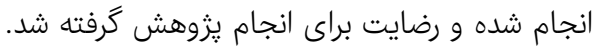

همسران مجروحان جنگ كه بهعنوان معلول يا مجروح تلقى

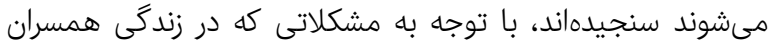

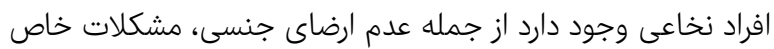

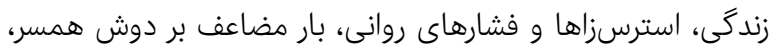

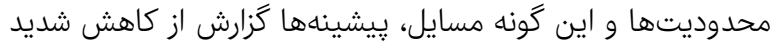

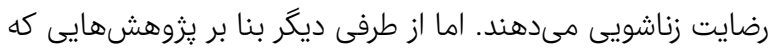

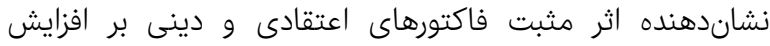
سازكارى و رضايت زناشويى است، مىبينيم كه همسران جانيت إنبازان

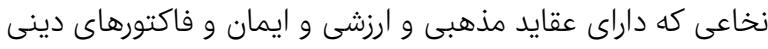

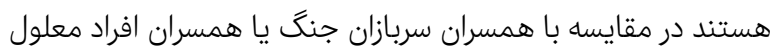

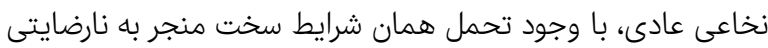

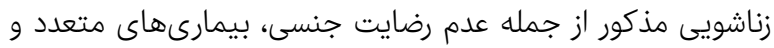

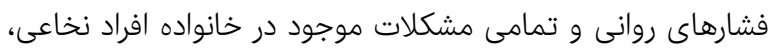

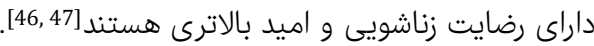

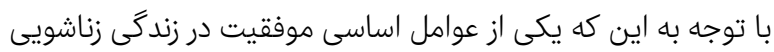
و كسب رضايت زناشويى داشتن ارتباط موثر با همسر شامل رابل رابطه

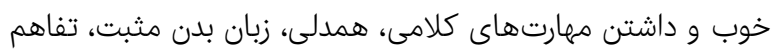

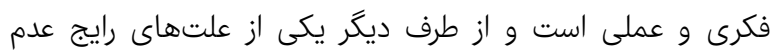

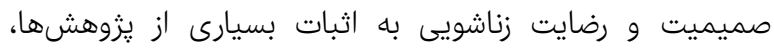

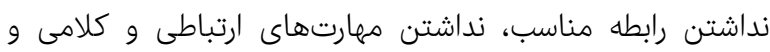

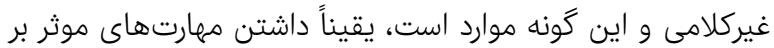

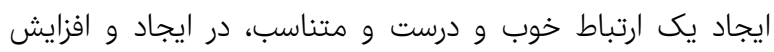

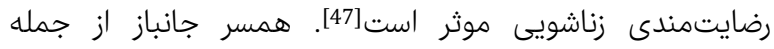

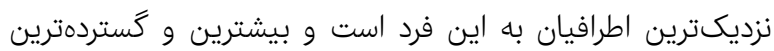

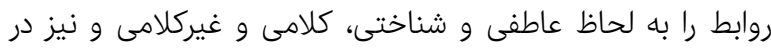

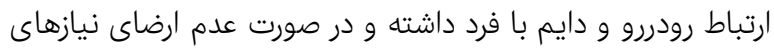

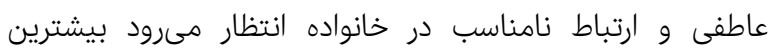

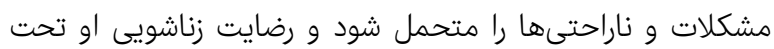

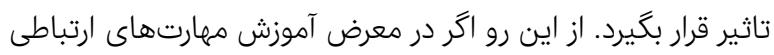

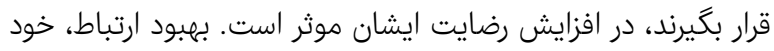

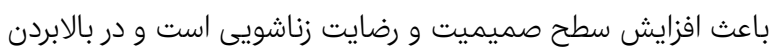
سطح اميد نيز موثر است.

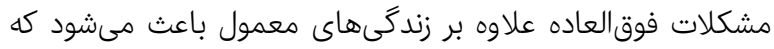

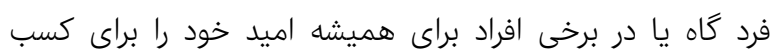

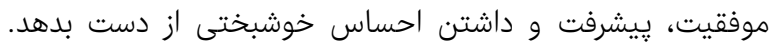

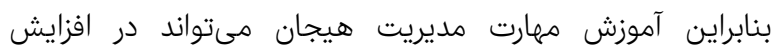

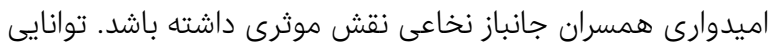

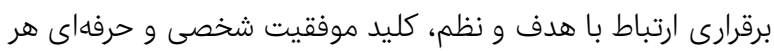

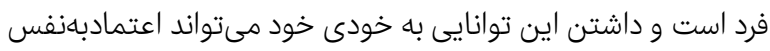

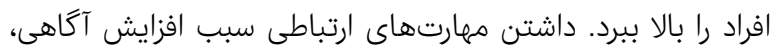

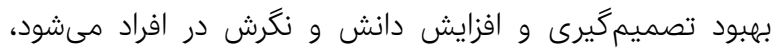

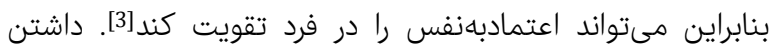
روابط نادرست و تنظيمنشده، نبود همدلى و توجه و و بى إحرمتى و

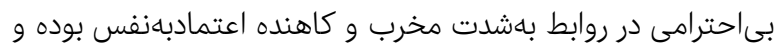


prevention of domestic violence. J Psychol cogn Psychiatry. 2016(3)2:21-32. [Persian]

15- Hashemi L, Ahmadi AH, Safvat MS, Azizi AK. Exploring the effect of life skills training on prisoners' psychological adjustment (depression, anxiety, stress, aggression, selfconfidence, and self-assertiveness). J Correct Educ. 2014;144:3-9. [Persian]

16- Shirpour AH, Ebrahimi Moghadam H. The effectiveness of life skills training on marital satisfaction and life expectancy of people with AIDS. J Psychol New Ideas. 2017;1(1):21-8. [Persian]

17- Plooy K, Beer R. Effective interactions: communication and high levels of marital satisfaction. J Psychol Afr. 2018;28(2):161-7.

18- Baby M, Gale C, Swain N. Communication skills training in the management of patient aggression and violence in healthcare. Aggress Violent Behav. 2018;39:67-82.

19- Sadati SZ, Mirzaian B, Dusti YA. The effect of life skills training on marital satisfaction and happiness of married female students. Soc Health J. 2018;5(3):282-90. [Persian] 20- Khodakarami B, Asadi R, Masoumi SZ, Soltanian A. Effect of life skills counseling on marital satisfaction of pregnant women referring to health clinics in Asadabad, Hamadan, Iran. J Clin Diagn Res. 2018;12(6):6-10.

21- Sajjadi S, Ghaderi Sanavi RA, Farhoudian A, Mohaghegh Kamal SH, Reza Soltani P, Azadchehr MJ. Effectiveness of Life Skills Training on Marital Satisfaction among Young Couples. J Soc Welfare. 2015;15(56):13349. [Persian]

22- Yoosefi N. Effectiveness of life skills training in marital satisfaction and couple's hopefulness. J Fam Psychol. 2016;3(1):59-70. [Persian]

23- Shirkvand N, Gholami Heidari S, Arab Salari Z, Ashouri J. The impact of life skills training on happiness and hopefulness among patients with type II diabetes. J Diabetes Nurs. 2015;(3)3:8-19. [Persian]

24- Kazemi A. Examining the effect of life skills training on increasing life expectancy of lifers in drug penitentiary of Mazandaran province. Global J New Media Educ. 2014;1(3):67-72. [Persian]

25- Salimi H, Azad Marzabadi E, Amiri M, Taghavi MR. Aspects of marital satisfaction among veterans' wives. J New Thoughts Educ. 2009;4(4):57-72. [Persian]

26- Dehghan F, Piri Kamrani M, Goli R, Rahmani H. The impact of life skills training on marital satisfaction, marital dissatisfaction and mental health of veteran's wife. J Woman Soc. 2017;7(28):1-12. [Persian]

27- Mohamadipour M, Falahati M. Effectiveness of life skills training on mental health of spouses of veterans with affective disorders. Iran J War Public Health. 2016;8(1):25-32. [Persian]

28- Falahati M, Shafiabadi A, Jajarmi M, Mohamadipoor M. Effectiveness of acceptance and commitment therapy and logotherapy on marital satisfaction of veterans' spouses. Iran J War Public Health. 2019;11(3):139-45. [Persian]

29- Sanaei B. Family and marriage assessment scales. $2^{\text {nd }}$ Edition. Tehran: Besat Press; 2008. [Persian]

30- Arab Alidoosti AR, Nakhaei N, Khanjani N. Reliability and validity of the Persian versions of the Enrich marital satisfaction (brief version) and Kansas marital satisfaction scales. Health Dev J. 2015;4(2):158-67. [Persian]

31- Snyder CR, Harris C, Anderson JR, Holleran SA, Irving LM, Sigmon ST, et al. The will and the ways: development and validation of an individual-differences measure of hope. J Pers Soc Psychol. 1991;60(4):570-85.

$$
\begin{aligned}
& \text { تعارض منافع: موردى از سوى نويسندكان گزارش نشار نشده است. }
\end{aligned}
$$

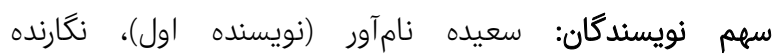

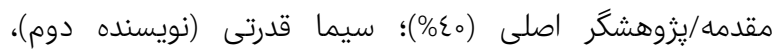

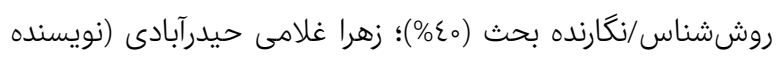

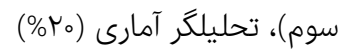

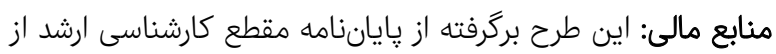

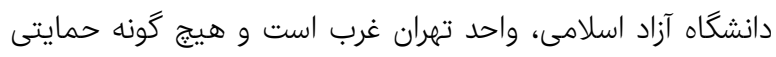

$$
\begin{aligned}
& \text { از سوى نهاد يا سازمان خاصى صورت نكُفته است. }
\end{aligned}
$$

1- Dehghani Firouzabadi SJ. Power technologies in the soft war. J Strateg Stud. 2011;(14)51:5-30. [Persian]

2- Sheikhan R, Hasanabadi HR, Sepahvandi MA, Mirdarikvand F. The effect of life skills training on the frequency of depressive mental ruminations among spouses of veterans. Jundishapur Sci Med J. 2017;15(6):697-706. [Persian]

3- Soleimanian AA, Jajermi M, Falahati M. The effectiveness of life skills training on the quality of life of spouses of veterans with affective disorders. Iran J War Public Health. 2015;7(4):197-205. [Persian]

4- Naderi Y, Moradi A, Hasani J, Noohi S. Effectiveness of emotional schema therapy on cognitive emotion regulation strategies of combat-related post traumatic stress disorder veterans. Iran J War Public Health. 2015;7(3):147-155. [Persian]

5- Pourheidari S, Bagherian F, Dustkam M, Bahadorkhan J. The effects of life skills training on marital and sexual satisfaction of young couples. J Knowledge Res Appl Psychol. 2013;14(51):14-22. [Persian]

6- Fallah S. The relationship between self-confidence and academic motivation in Chalus Azad University students. J New Adv Psychol Train Educat. 2019;2(15):90-6. [Persian]

7- Jalaei F. The effect of acceptance and commitment therapy on forgiveness and life expectancy of drugs dependents. J Educ Psychol Stud. 2017;3(4):1-22. [Persian]

8- Khodabakhsh MR, Mansouri P. The effect of life skills education on psychological health. Zahedan J Res Med Sci. 2011;13(3):51. [Persian]

9- Bahari S, Shafighpour MR. The effect of life skills training on students' mental health. 2005;1(1):25- 37. [Persian]

10- Romas JA. Sharma M. Practical stress management: a comprehensive workbook. $7^{\text {th }}$ Edition. Saint Louis: Elsevier Science; 2017. p. 69-89.

11- hPlutchik R. Plutchik's wheel of emotions [Internet]. United Stetes: Sixseconds; 2017 [cited 2019 May 17]. Available from: https://www.6seconds.org/2017/04/27/plutchiksmodel-of-emotions/

12- Desatnik A, Bel-Bahar T, Nolte T, Crowley M, Fonagy P, Fearon P. Emotion regulation in adolescents: an ERP study. Biol Psychol. 2017;129:52-61.

13- Nouripour Layavli R, Zadeh Mohamadi A, Dastres M, Sargolzaei M. The effectiveness of life skills training on enhancement of self-esteem and marital satisfaction among addicts in treatment period. J Res Addict. 2014;29(8):37-48. [Persian]

14- Naeem M, Rezaei Sharif A. The efficacy of life skills training on marital adjustment of women for the 


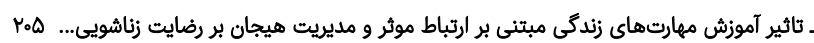

41- Kaveh Farsani Z, Ahmadi SA, Fatehizadeh M. The effect of life skills training on marital satisfaction and adjustment of married women in rural areas of Farsan. J Fam Couns Psychother. 2012;2(3):373-87. [Persian] 42- Sajedi S, Atashpour SH, Kamakar M, Samsam Shariat MR. The effect of life skills training on interpersonal relationship, self esteem and assertiveness of blind girls in the Fatemeh Zahra institute of Isfahan. J Knowledge Res Appl Psychol. 2009;11(39):14-26. [Persian] 43- Karami Baghteyfouni Z, Farnoodian P, Vafa S, Chegini $M$, Khaledian M. Efficacy of training life skills on reducing depression and increasing life expectancy in of the addicts. Adv Envir Biol. 2014;8(10):1008-14.

44- Lavner JA, Karney BR, Bradbury TN. Does couples' communication predict marital satisfaction, or does marital satisfaction predict communication? J Marriage Fam. 2016;78(3):680-94.

45- Kim Halford W, Pepping CA, Hilpert P, Bodenmann G, Wilson KL, Busby D, et al. Immediate effect of couple relationship education on low-satisfaction couples: a randomized clinical trial plus an uncontrolled trial replication. Behav Ther. 2015;46(3):409-21.

46- Bjørshol CA, Lindner TW, Søreide E, Moen L, Sunde K. Hospital employees improve basic life support skills and confidence with a personal resuscitation manikin and a 24-min video instruction. Resuscitation. 2009;80(8):898902.

47- Hasanzadeh R, Mirian SA, Lazgi F. Studying the relationship between the trust in God and the quality of life and life expectancy of Teachers of high schools in Teaching and Education center, first area of Sari City. Isalam Health J. 2014;1(2):15-21. [Persian]

48- Mahmoodi Rad M, Arasteh HR, Afgheh S, Barati Sade F. The role of communication skills training and social problem solving on the self-esteem and intelligence of third-year elementary school students. J Rehabil. 2007;8(29):69-74. [Persian]
32- Khaledian M, Mohamadifar MA. Effectiveness of group cognitive-behavioral therapy and logotherapy in reducing depression and increasing life expectancy in drug addicts. J Res Addict. 2016;9(36):63-80. [Persian]

33- Kermani Z, Khodapanahi MK, Heidari M. Psychometric characteristics of Schneider scale. J Appl Psychol. 2011;5(3):7-23. [Persian]

34- Javadi F, Nasoohian H. Comparison of selfconfidence and mental health in overactive and healthy children 6-12 years old in primary schools in Qom. In: Proceedings of the Third National Conference on Psychology and Behavioral Sciences; 2015 Aug 13; Narkish Information Institute, Tehran, Iran. Tehran: Civilica; 2015. [Persian]

35- Bahramian M. An evaluation of the reliability and validity and standardization of Bernreuter Personality Inventory [Dissertation]. Tehran: Islamic Azad University Tehran Branch; 2000. [Persian]

36- Gibby RE, Zickar MJ. A history of the early days of personality testing in American industry: an obsession with adjustment. Hist Psychol. 2008;11(3):164-84.

37- Jalali D, Nazari A. Effects of social learning model training on self- esteem, self- confidence, self assertiveness and academic achievement in third grade students of intermediary schools. J Res Behav Sci. 2009;7(1):43-53. [Persian]

38- Gross JJ. Emotion regulation: affective, cognitive and social consequences. Psychophysiology. 2002;39(3):28191.

39- Miller S, Miller P, Nunnally EW, Wackman DB. Talking and listening together: couple communication one. Bahadori F, translator. 1st Edition. Tehran: Roshd; 2004. [Persian]

40- Tavakoli zadeh J, Nejatian M, Suri A. The effectiveness of communication skills training on marital conflicts and its different aspects in women. Proceeda Soc Behav Sci. 2015;171:214-21. 